\title{
HISTORY OF ORTHODONTIC TREATMENT, TREATMENT NEEDS AND INFLUENCING FACTORS IN ADOLESCENTS IN CROATIA
}

\author{
Stjepan Špalj ${ }^{1}$, Višnja Katić1, Renata Vidaković ${ }^{2}$ Martina Šlaj², Mladen Šlaj ${ }^{2}$ \\ 'Department of Orthodontics, School of Medicine, University of Rijeka, Rijeka, Croatia \\ ${ }^{2}$ Department of Orthodontics, School of Dental Medicine, University of Zagreb, Zagreb, Croatia
}

\section{SUMMARY}

Aim: The aim of this study was to assess the orthodontic treatment needs of adolescents in Zagreb, Croatia, in relation to their orthodontic treatment history, caries experience and socio-demographic parameters.

Methods: The study sample comprised 1,289 adolescents from 12 randomly selected public schools in Zagreb, Croatia. The subjects were 15-18 years old (mean age $16.3 \pm 1.4$ ), and $51 \%$ of them were girls. The Dental Aesthetic Index (DAl), the sum of the numbers of decayed, missing and filled teeth (DMFT index), and a questionnaire (covering socio-demographic issues, oral health-related attitudes and behaviours) were employed in this study. The data was analyzed by means of Chi-square test, analysis of variance, and multiple logistic regression models.

Results: The DMFT score was higher in adolescents with no orthodontic history $(5.2 \pm 3.7)$ than in those who were under orthodontic treatment at the time of the research $(4.5 \pm 3.2 ; p=0.043)$. More than $60 \%$ of the adolescents have never undergone any orthodontic treatment, around $24 \%$ previously undergone treatment and $15 \%$ were under treatment at the time of the research. Overall, $85 \%$ of the adolescents' orthodontic appliances were removable, and the girls were more often under orthodontic treatment. One fifth of the studied population had severe or very severe malocclusion. Adolescents with previous orthodontic treatment were more often interested in better teeth alignment, changes in their teeth positioning and continuing orthodontic treatment. Multiple logistic regression model demonstrated that previously treated adolescents, in comparison with their untreated peers, were on average older $(p=0.002)$, were less satisfied with the appearance of their teeth $(p=0.001)$, they had higher malocclusion severity $(p=0.046)$, and fewer dental caries $(p<0.001)$, changed toothbrushes more often $(p=0.012)$, and their mothers attained higher education $(p<0.001)$.

Conclusions: Although many adolescents received orthodontic treatment, the severity of their malocclusion was still somewhat high, and they were more often dissatisfied with their treatment outcome. Mothers' educational level was found to be the most important socio-demographic predictor for children's involvement in orthodontic treatment. The caries experience increased in comparison with the Croatian national survey data from 1999.

Key words: malocclusion, caries, dental public health, orthodontic treatment need, orthodontic treatment history, socio-demographic characteristics

Address for correspondence: V. Katić, Department of Orthodontics, School of Medicine, University of Rijeka, Kresimirova 40, 51000 Rijeka, Croatia. E-mail: visnja.katic@medri.uniri.hr

http://dx.doi.org/10.21101/cejph.a4117

\section{INTRODUCTION}

In Croatia, public health fund has been utilized for decades for the treatment of malocclusions of all persons up to 18 years of age. In order to reduce this expenditure and simultaneously improve the quality of treatment and identify groups in greater need for such treatment, a survey among concerned population was conducted.

Prior to orthodontic malocclusion treatment, it is important to consider patient's point of view and to appropriately set treatment priorities (1-6). In determining treatment needs, the existing orthodontic indices emphasize the importance of the aesthetic component of malocclusions and the need to consider the psychosocial impact on patients' well-being (7-11).

The Dental Aesthetics Index (DAI) was conceived to assess the degree of dental discrepancies in relation to aesthetic concern, judged by the aesthetic understanding of the lay person with permanent dentition (7). Using DAI is easy and fast, and its relevance to judging the orthodontic treatment need is proved. Besides comparison with other research findings it is also appropriate for assessment of public health needs and policy making (12-15).

The simple, fast and most often used method for assessing dental health status is the sum of the numbers of decayed, missing and filled teeth (DMFT index) $(16,17)$. This index demonstrates caries experience and is used to set goals for dental health improvement and formulating dental health policies. The DMFT also identifies the groups of people, who need more attention in order to improve their dental health status (18-22).

Socio-demographic aspects deserve consideration in public health surveys, as they help in understanding the inequalities in access to information, education, and health services, particularly the speciality treatments (20-24).

The aim of this study was to assess the orthodontic treatment needs of the adolescents in Zagreb, Croatia, in relation to their orthodontic treatment history, caries experience and sociodemographic parameters. 


\section{MATERIALS AND METHODS}

\section{Sampling and Examination}

Data was collected from September 2006 to February 2007, during an epidemiological study conducted in 12 secondary public schools, randomly selected from 55 public schools in Zagreb, Croatia, using the cluster sampling procedure with special attention to location and type of school (general, technical and crafts). The sample comprised 1,289 subjects, $51 \%$ of them girls, aged $15-18$ years (mean age $16.3 \pm 1.4$ ). It covered approximately 5 percent of the population of students of that age in Zagreb. At this age adolescents have permanent dentition and they can be treated with either removable or fixed orthodontic appliances. University and governmental boards of ethics approved the survey and the students and their parents gave the informed consents for the survey. Malocclusions and treatment needs were assessed using DAI. Information on examinees' orthodontic treatment history and their satisfaction level with their dental appearance were collected through interviews. Four previously educated and calibrated examiners performed intra-oral examinations using the WHO Community Periodontal Index probe, mouth mirror and artificial lighting placed on the examiner's head. No radiographs or study casts were used.

\section{Socio-demographic Features}

The questionnaire had three subdivisions:

- Oral health-related behaviour (undergoing regular dental check-ups; tooth brushing and flossing; replacing toothbrush; wearing sports' mouth guards; consuming sweets, sweet beverages, tobacco and alcohol; following oral hygiene instructions; knowing the correct way of tooth brushing; being alert about gingivitis);

- Oral health-related knowledge and attitudes (whether it is normal for teeth to loosen and fall out at old age; should one pull out all teeth to prevent future problems; is it better to heal or pull out the tooth that hurts; is tooth brushing necessary);

- Socio-economic status (educational status of the parents; number of brothers and sisters; housing condition; financial status; number of cars; frequency of vacations).

\section{Statistical Methods}

Differences in treatment needs between genders and treatment groups were analysed by means of Chi-square test and those in DMFT and age by using the ANOVA with post hoc tests (Scheffe for equal variances and Games-Howell for unequal variances). Multiple logistic regression models were used to establish the association between orthodontic history, malocclusion severity, oral health, dental hygiene habits, and socio-demographic characteristics. Presence of a particular factor was used as a dichotomized variable $(0=$ no/absent, $1=$ yes/present $)$. Components of DMFT, frequency of dental check-ups, tooth brushing, brush replacement, parents' education level, financial status, and age were included in the analysis as continuous independent variables. Gender was also considered $(0=$ girls, $1=$ boys $)$. The odds ratios $(\mathrm{OR})$, with $95 \%$ confidence interval limits $(\mathrm{CI})$, were used as a measure of the strength of association indicating statistically significant relationships if the values were either greater or less than 1 . The significance of effects in the model was assessed using the Likelihood ratio test. All analyses were carried out using commercial software (SPSS 10.0; SPSS Inc., Chicago, Illinois, USA), and the statistical significance was pre-set at $\mathrm{p}<0.05$.

\section{RESULTS}

The inter- and intra-examiner reliabilities were evaluated by repeated measurements on 10 subjects with a 7-day interval between the first examination and the next one. The extent of agreement was found to be above $80 \%$ (Intra-class correlation coefficient, $r=0.87$, Cohen Kappa $=0.64, \mathrm{p}<0.001)$.

More than $60 \%$ of the Zagreb's students aged $15-18$ years have never received any orthodontic treatment, around $24 \%$ were previously treated, and $15 \%$ were receiving orthodontic treatment at the time of the research (Table 1). The subjects more often underwent treatment with removable orthodontic appliances, $85 \%$ of the students with previous or current orthodontic treatment had only these appliances (Table 1). Among the examinees, girls, both previously treated and those being treated at the time of this research, were more often orthodontically treated than boys $(p<0.05)$. ANOVA analysis showed that previously treated students were on average older than both untreated and those being treated at the time of this research $(\mathrm{p}<0.05)$ (Table 2).

Considering caries experience, students, who have never received any orthodontic treatment, had on average a higher DMFT score compared to students who were receiving orthodontic treatment at the time of this research; also, the former had more decayed and missing teeth, but fewer filled teeth than the latter (Table 2).

Almost two third of the surveyed population had no or only minor malocclusion in contrast to one fifth of the population who had severe or very severe malocclusion (Fig. 1). Very severe malocclusions were most often found in students who were receiving orthodontic treatment at the time of this research, and most rarely in students who have never received any orthodontic treatment (Fig. 1). Malocclusions were evenly distributed among both genders. Besides, one quarter of the students never treated for malocclusion was also examined by an orthodontist at some point in their life.

Table 1. Distribution of examinees according to history of orthodontic treatment and type of orthodontic appliance used

\begin{tabular}{|l|c|c|c|}
\hline Orthodontic treatment & Removable appliances & Fixed appliances & Total \\
\hline Previously treated & $276(90.2 \%)$ & $30(9.8 \%)$ & $306(23.7 \%)$ \\
\hline Currently treated & $148(76.7 \%)$ & $45(23.3 \%)$ & $193(15 \%)$ \\
\hline Never treated & - & - & $790(61.3 \%)$ \\
\hline Total & $424(32.9 \%)$ & $75(5.8 \%)$ & 1,289 \\
\hline
\end{tabular}




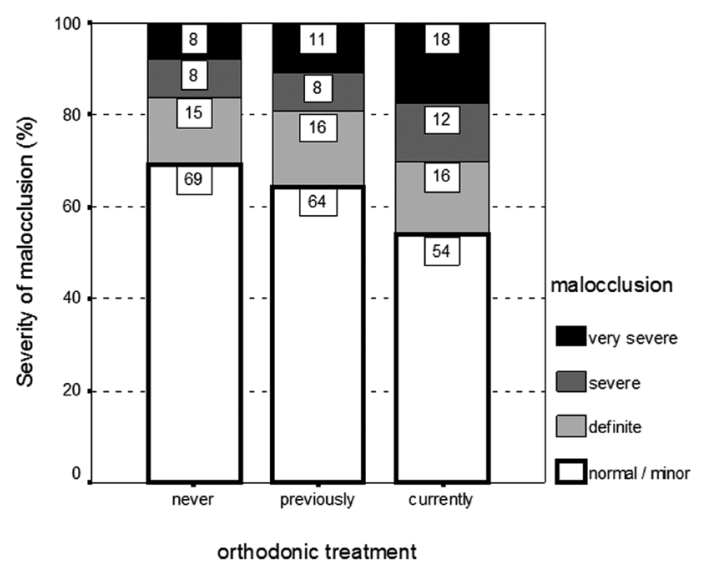

Fig. 1. Distribution of malocclusion severity in treatment groups according to Dental Aesthetic Index (DAI).

The Chi-square test showed significant differences in prevalence of malocclusion severity groups among the three orthodontic treatment history groups $(p=0.001)$. No difference was found between untreated and previously treated students. The untreated students of both genders had less frequently very severe and severe malocclusion and more minor malocclusions when compared to the students who were under treatment at the time of this research $(p<0.001)$, while differences in malocclusion severity between previously treated group and the group under treatment at the time of this research were found only in girls $(\mathrm{p}=0.044)$.

Students with previous orthodontic treatment were more often wished for more aligned teeth, remained favourably disposed to change something about their teeth positioning and were under the impression that they still need orthodontic treatment (all at $p<0.001$ ). History of orthodontic treatment at every degree of the malocclusion severity was related to the gender $(p<0.05)$. Boys were more often untreated than girls at every degree of malocclusion; while those with present severe and very severe malocclusion were mostly previously treated. At the time of this research, girls were more often treated for all degrees of malocclusion represented mainly in minor and definite malocclusion groups of previously treated students.

Multiple logistic regression models show that previously treated students in comparison with their untreated peers were on average older and less satisfied with the appearance of their teeth; they had fewer caries and higher severity of malocclusion. Besides, their mothers attained higher educational degrees. Also, they changed their toothbrushes more often than did the untreated students (Table 3). Statistical analysis does not show any differences between untreated and previously treated students in terms of other components of their oral health related behaviour and knowledge, as well as their socio-economic status.

\section{DISCUSSION}

Students, who previously underwent orthodontic treatment, had fewer decayed and missing teeth, but more filled teeth. This may be because they enjoyed, besides their concern for the status of their teeth, the privilege of frequent controls by specialist doctors. The DMFT score of Croatian adolescents is still far from the goals set by the WHO in 2000 (22), and therefore the focus

Table 2. Distribution of age and the number of decayed, missing, and filled teeth (DMFT) in relation to history of orthodontic treatment

\begin{tabular}{|l|c|c|c|c|c|c|c|}
\hline & $\begin{array}{c}\text { Never (1) } \\
\mathbf{N}=790\end{array}$ & $\begin{array}{c}\text { Previously (2) } \\
\mathbf{N}=306\end{array}$ & $\begin{array}{c}\text { Currently (3) } \\
\mathbf{N}=193\end{array}$ & $\mathbf{p}^{*}$ & $\mathbf{p ~ 1 - 2}$ & $\mathbf{p ~ 2 - 3}$ & $\mathbf{p ~ 1 - 3}$ \\
\hline Age & $16.2 \pm 1.4$ & $16.6 \pm 1.4$ & $16.3 \pm 1.3$ & $<0.001$ & $<0.001$ & 0.016 & $\mathrm{~ns}$ \\
\hline DT & $1.9 \pm 2.5$ & $1.1 \pm 2.0$ & $0.6 \pm 1.2$ & $<0.001$ & $<0.001$ & 0.003 & $<0.001$ \\
\hline MT & $0.3 \pm 0.7$ & $0.1 \pm 0.6$ & $0.1 \pm 0.4$ & 0.002 & 0.029 & $\mathrm{~ns}$ & $<0.001$ \\
\hline FT & $3.0 \pm 2.8$ & $3.9 \pm 3.1$ & $3.8 \pm 3.0$ & $<0.001$ & $<0.001$ & $\mathrm{~ns}$ & 0.010 \\
\hline DMFT & $5.2 \pm 3.7$ & $5.1 \pm 3.7$ & $4.5 \pm 3.2$ & 0.041 & $\mathrm{~ns}$ & $\mathrm{~ns}$ & 0.043 \\
\hline
\end{tabular}

${ }^{*}$ ANOVA + Post hoc Scheffe (equal variances) or Games - Howell (unequal variances).

Table 3. Associations between orthodontic history ( $0=$ never treated, $1=$ previously treated) and malocclusion severity (Dental Aesthetic Index - DAl score), oral health related behaviour and knowledge, socioeconomic status and satisfaction with dental appearance considering the effect of gender ( $0=$ females, $1=$ males) as estimated by the logistic regression model. Only statistically significant variables are listed

\begin{tabular}{|l|l|c|c|c|c|}
\hline Dependent variable & Independent variable & Logistic coefficient & Standard error & Sig. (p) & Odds ratio (95\% Cl) \\
\hline \multirow{5}{*}{ Previously treated } & Age & 0.171 & 0.054 & 0.002 & $1.2(1.07-1.32)$ \\
\cline { 2 - 6 } & Decayed teeth & -0.185 & 0.039 & $<0.001$ & $0.8(0.77-0.90)$ \\
\cline { 2 - 6 } & Mother's education & & 0.141 & $<0.001$ & $1.6(1.25-2.16)$ \\
\cline { 2 - 6 } & Brush replacement* & -0.494 & 0.115 & 0.012 & $0.8(0.60-0.94)$ \\
\cline { 2 - 6 } & DAl score & 0.019 & 0.009 & 0.046 & $1.0(1.00-1.04)$ \\
\cline { 2 - 6 } & Satisfaction = yes & -0.582 & 0.169 & 0.001 & $0.6(0.40-0.78)$ \\
\hline
\end{tabular}

Cox \& Snell pseudo $\mathrm{R}^{2}=0.074$

*1 - elementary school or less, 2 - secondary school, 3 - university or higher

** 1 - every to 3 months, 2 - every $3-6$ months; 3 - every $6+$ months 
should be on caries prevention in future Croatian public dental health and education plans. According to the DMFT score in Croatia, there was an improvement in children from rural areas (25), in contrast to the deterioration in Zagreb's children, when compared to the Croatian national survey data from 1999 (26). Present study shows that dental health care continues to be individually oriented and that primarily mothers care about their children's dental health. Besides, it corroborates the correlation already established $(27,28)$ between mothers' socio-demographic characteristics and successful implementation of positive oral hygiene habits. Henceforth, future public health model should be oriented more toward family and also further developed so as to include more contemporary methods for public dental health education, as suggested in recent studies $(29,30)$. Both fixed and removable orthodontic appliances register increase in bacterial microflora associated with early stages of caries caused by poor dental hygiene $(31,32)$. But, in the case of students with orthodontic history, the children's concern for their teeth probably contributed to the lower caries experience (33).

The distribution patterns of malocclusion severity degrees between the untreated students and those who previously had orthodontic treatment were similar. The need for residual treatment in previously treated students remained unsatisfactorily high (19\% for severe and very severe malocclusions, and up to $35 \%$, if the definite malocclusion group is included), in contrast to that in Sweden (2\%) (34). The factors that could have led to failure in achieving more effective reduction in malocclusions are discontinuation of treatment induced by patients (those cases were not excluded from this study), less-motivated boys (with higher percentage of severe and very severe malocclusion in both untreated and previously treated groups), and removable appliances used in the majority of treatments. Miethke and Wronski (35) studied the outcome of treatment that was completed according to plan, employing solely removable appliances. Their therapy spread over an average duration of 52 months and resulted in great improvement, in relation to pre-existing malocclusion, in only $16 \%$ of patients, improvement in $79 \%$ of patients, and neither improvement nor deterioration in $5 \%$ of patients (35). In terms of the appliances used, $83 \%$ of the patients were treated with active plates and functional appliances, $12 \%$ only with functional appliances and 4\% solely with plates; on the average, five appliances were used per patient. The success rate of the appliance declined with increase of patients' age. Sagittal aspect of occlusion was the most difficult one to correct, and at the end of treatment, $58 \%$ of the patients continued to have an occlusion deviant from Class I (35). Several studies reported that the overall percentage of improvement, after completion of treatment with removable appliances, was in the range of 39-68\% (35-38). Better treatment results were achieved by using fixed orthodontic appliances (34, 39). The factors often associated with discontinuation of treatment and lack of cooperation from the patient are the use of removable appliances and enrolment for orthodontic treatment at an early age. Also, the treatment was often offered to children whose compliance and perception of treatment need are poor. Those who treat the patients should be aware of the patients' perceptions regarding their aesthetic ideals and orthodontic history $(40,41)$. Besides, better ways of motivating the schoolchildren should be explored, with special emphasis on adolescent male population. Also, the therapy should use more fixed orthodontic appliances, because most of the already treated students were unsatisfied with appearance and alignment of their teeth.

To prevent possible increase in caries incidence (caused by poor hygiene around fixed appliances), the importance and effectiveness of oral hygiene should be discussed and demonstrated more often to the target population. Regular dental check-ups of students should be more frequent.

Almost $40 \%$ of the students received orthodontic treatment; a similar trend was observed even earlier (42). The data presented in this paper on the prevalence and severity of malocclusions is assessed on the representative sample of the Zagreb's adolescent population and can be used for projecting publicly subsidized treatment expenses. If there are established guidelines for fixing treatment priorities in Croatian dental health system, based on the DAI scores for very severe and severe malocclusions, $21.7 \%$ of students would qualify for publicly subsidized treatment. Furthermore, more than half $(12.2 \%)$ of such students would be considered as having very severe or handicapping malocclusion. This calls for regulation of dental health care system in Zagreb and Croatia by evolving suitable regulation criteria. The criteria must cover determination of treatment priorities, control of treatment standards, and quality of outcomes. Further studies, involving additional age groups and the outcomes of therapy in orthodontically treated population are needed, besides exploring the reasons for drop-outs.

The data presented in the study served as the initiative for introducing appropriate changes in the financing of orthodontic therapy through public health system. The new criteria for enrolment in orthodontic therapy, financed by the state insurance, came into effect in 2014, and the outcomes of these changes should be evaluated in future studies.

\section{Acknowledgements}

This study was conducted as a part of project "Reorganization and modernization of orthodontic services in the City of Zagreb, based on evaluation of orthodontic treatment needs of schoolchildren, and epidemiological survey and quality assessment". The study was supported by Zagreb City Municipal grant, and Croatian Ministry of Science, Education and Sport grant given to Professor Mladen Šlaj, Head of Projects, and Professor Stjepan Špalj, Principal Investigator, University of Rijeka's research project No. 13.06.2.1.53 "Predictors for success of orthodontic treatment in children and adolescents".

\section{Conflict of Interests}

None declared

\section{REFERENCES}

1. Tsakos G. Combining normative and psychosocial perceptions for assessing orthodontic treatment needs. J Dent Educ. 2008 Aug;72(8):876-85.

2. Liu Z, McGrath C, Hägg U. The impact of malocclusion/orthodontic treatment need on the quality of life. A systematic review. Angle Orthod. 2009 May;79(3):585-91.

3. Manjith CM, Karnam SK, Manglam S, Praveen MN, Mathur A. Oral Health-Related Quality of Life (OHQoL) among adolescents seeking orthodontic treatment. J Contemp Dent Pract. 2012 May 1;13(3):294-8.

4. Palomares NB, Celeste RK, Oliveira BH, Miguel JA. How does orthodontic treatment affect young adults' oral health-related quality of life? Am J Orthod Dentofacial Orthop. 2012 Jun;141(6):751-8. 
5. Johal A, Alyaqoobi I, Patel R, Cox S. The impact of orthodontic treatment on quality of life and self-esteem in adult patients. Eur J Orthod. 2015 Jun;37(3):233-7.

6. Danyluk K, Lavelle C, Hassard T. Potential application of the dental aesthetic index to prioritize the orthodontic service needs in a publicly funded dental program. Am J Orthod Dentofacial Orthop. 1999 Sep;116(3):27986.

7. Cons NC, Jenny J, Kohout FJ. DAI: the dental aesthetic index. Iowa City: University of Iowa; 1986.

8. Jenny J, Cons NC, Kohout FJ, Jakobsen J. Predicting handicapping malocclusion using the Dental Aesthetic Index (DAI). Int Dent J. 1993 Apr;43(2):128-32.

9. Shaw WC, Richmond S, O'Brien KD. The use of occlusal indices: a European perspective. Am J Orthod Dentofacial Orthop. 1995 Jan;107(1):1-10

10. Jenny J, Cons NC. Comparing and contrasting two orthodontic indices, the Index of Orthodontic Treatment need and the Dental Aesthetic Index. Am J Orthod Dentofacial Orthop. 1996 Oct;110(4):410-6.

11. Beglin FM, Firestone AR, Vig KW, Beck FM, Kuthy RA, Wade D. A comparison of the reliability and validity of 3 occlusal indexes of orthodontic treatment need. Am J Orthod Dentofacial Orthop. 2001 Sep;120(3):240-6.

12. Shaw WC, Richmond S, O'Brien KD, Brook P, Stephens CD. Quality control in orthodontics: indices of treatment need and treatment standards. Br Dent J. 1991 Feb 9;170(3):107-12.

13. Spencer AJ, Allister JH, Brennan DS. Utility of the dental aesthetic index as an orthodontic screening tool in Australia. Adelaide: University of Adelaide; 1992

14. Burden DJ, Holmes A. The need for orthodontic treatment in the child population of the United Kingdom. Eur J Orthod. 1994 Oct;16(5):395-9.

15. Cardoso CF, Drummond AF, Lages EM, Pretti H, Ferreira EF, Abreu MH. The Dental Aesthetic Index and dental health component of the Index of Orthodontic Treatment Need as tools in epidemiological studies. Int J Environ Res Public Health. 2011 Aug;8(8):3277-86.

16. Klein H, Palmer CE, Knutson JW. Studies on dental caries I. Dental status and dental needs of elementary school children. Public Health Rep. 1938;53(19):751-65.

17. World Health Organization. Oral health surveys: basic methods. Geneva: WHO; 1997.

18. Featherstone JD. Dental caries: a dynamic disease process. Aust Dent J. 2008 Sep;53(3):286-91

19. Borzabadi-Farahani A, Eslamipour F, Asgari I. Association between orthodontic treatment need and caries experience. Acta Odontol Scand. 2011 Jan;69(1):2-11.

20. Piovesan C, Pádua MC, Ardenghi TM, Mendes FM, Bonini GC. Can type of school be used as an alternative indicator of socioeconomic status in dental caries studies? A cross-sectional study. BMC Med Res Methodol. 2011 Apr 2;11:37. doi: 10.1186/1471-2288-11-37.

21. Mtaya M, Brudvik P, Astrøm AN. Prevalence of malocclusion and its relationship with socio-demographic factors, dental caries, and oral hygiene in 12- to 14-year-old Tanzanian schoolchildren. Eur J Orthod. 2009 Oct;31(5):467-76

22. Aggeryd T. Goals for oral health in the year 2000: cooperation between WHO, FDI and the national dental associations. Int Dent J. 1983 Mar;33(1):55-9.

23. Pietilä I, Pietilä T, Svedström-Oristo AL, Varrela J, Alanen P. Orthodontic treatment practices in Finnish municipal health centres with differing timing of treatment. Eur J Orthod. 2009 Jun;31(3):287-93.

24. Josefsson E, Bjerklin K, Lindsten R. Self-perceived orthodontic treatment need and prevalence of malocclusion in 18- and 19-year-olds in Sweden with different geographic origin. Swed Dent J. 2010;34(2):95-106.
25. Jurić H, Klarić T, Zagar M, Buković D Jr, Janković B, Spalj S. Incidence of caries in children of rural and subrural areas in Croatia. Coll Antropol. 2008 Mar;32(1):131-6.

26. Rajić Z, Radionov D, Rajić-Mestrović S. Trends in dental caries in 12 year old children in Croatia. Coll Antropol. 2000 Jul;24 Suppl 1:21-4.

27. Finlayson TL, Siefert K, Ismail AI, Sohn W. Maternal self-efficacy and 1-5-year-old children's brushing habits. Community Dent Oral Epidemiol. 2007 Aug;35(4):272-81.

28. Saied-Moallemi Z, Virtanen JI, Ghofranipour F, Murtomaa H. Influence of mothers' oral health knowledge and attitudes on their children's dental health. Eur Arch Paediatr Dent. 2008 Jun;9(2):79-83.

29. Walker KK, Steinfort EL, Keyler MJ. Cues to Action as Motivators for Children's Brushing. Health Commun. 2015;30(9):911-21.

30. Angelopoulou MV, Oulis CJ, Kavvadia K. School-based oral healtheducation program using experiential learning or traditional lecturing in adolescents: a clinical trial. Int Dent J. 2014 Oct;64(5):278-84.

31. Batoni G, Pardini M, Giannotti A, Ota F, Giuca MR, Gabriele M, et al Effect of removable orthodontic appliances on oral colonisation by mutans streptococci in children. Eur J Oral Sci. 2001 Dec;109(6):388-92.

32. Richter AE, Arruda AO, Peters MC, Sohn W. Incidence of caries lesions among patients treated with comprehensive orthodontics. Am J Orthod Dentofacial Orthop. 2011 May;139(5):657-64.

33. Madléna M. The importance and possibilities of proper oral hygiene in orthodontic patients. In: Bourzgui F, editor. Orthodontics - basic aspects and clinical considerations. Rijeka: InTech; 2012. p. 69-110.

34. Bjerklin K, Lindsten R, Tunge JS, Sjövall C. Orthodontic treatment need, outcome and residual treatment need in 15 - and 20-year-olds. Swed Dent J. 2012;36(3):157-65.

35. Miethke RR, Wronski C. What can be achieved with removable orthodontic appliances? J Orofac Orthop. 2009 May;70(3):185-99.

36. Turbill EA, Richmond S, Wright JL. A closer look at General Dental Service orthodontics in England and Wales. I: Factors influencing effectiveness. Br Dent J. 1999 Aug 28;187(4):211-6.

37. Firestone AR, Häsler RU, Ingervall B. Treatment results in dental school orthodontic patients in 1983 and 1993. Angle Orthod. 1999 Feb;69(1):1926.

38. Richmond S, Shaw WC, Stephens CD, Webb WG, Roberts CT, Andrews M. Orthodontics in the general dental service of England and Wales: a critical assessment of standards. Br Dent J. 1993 May 8;174(9):315-29.

39. Lilja-Karlander E, Kurol J. Outcome of orthodontic care in 19-year-olds attending the Public Dental Service in Sweden: residual need and demand for treatment. Swed Dent J. 2003;27(2):91-7.

40. Spalj S, Slaj M, Varga S, Strujic M, Slaj M. Perception of orthodontic treatment need in children and adolescents. Eur J Orthod. 2010 Aug;32(4):387-94

41. Cala L, Spalj S, Slaj M, Lapter MV, Slaj M. Facial profile preferences differences in the perception of children with and without orthodontic history. Am J Orthod Dentofacial Orthop. 2010 Oct;138(4):442-50.

42. Radica N. Demand of orthodontic treatment using index of orthodontic treatment need (IOTN) [dissertation]. Zagreb: University of Zagreb; 2005.

Received September 24, 2014 Accepted in revised form July 9, 2015 